\title{
Optimal Scheduling of Delivery Plans in an Integrated Vendor - Buyer Inventory Model with Constant Deterioration and Three Phase Ramp Type Demand
}

\author{
Savitha $^{1}$ and Dr. K. K. Achary ${ }^{2}$ \\ ${ }^{1}$ Department of Engineering Mathematics, Shree Devi Institute of Technology, Mangalore, 574142, Karnataka, India. \\ ${ }^{2}$ Yenepoya Research Centre, Yenepoya (Deemed to be University), Deralakatte, 575018, Karnataka, India.
}

\begin{abstract}
:
Demand for certain type of products is considered to follow three different phases - initial phase of increasing demand, second phase of steady demand and third phase of decreasing demand when the product becomes outdated and it becomes zero. This phenomenon is generally known as three phase ramp type demand. This form of demand function is commonly used to describe the demand for fashion goods. Hence it is also necessary to study the effects of three phase ramp type demand rate in a supply chain system. In this paper, we have studied a vendor - buyer integrated inventory system when the demand rate follows ramp type in three phases and the items in the inventory deteriorate at a constant rate. Shortage of inventory is not considered. An analytical solution is obtained and it is validated by a numerical example. Sensitivity analysis of the optimal solution is carried out to study the effects of changes in the values of different parameters in the model.
\end{abstract}

Keywords: Integrated inventory system, constant deterioration, vendor-buyer, multiple deliveries, ramp type demand.

\section{INTRODUCTION}

The new global market requires long term close cooperation between vendor and buyer for their successful business. Trust between the vendor and buyer would develop over time due to various factors, such as, quality of items, adherence to delivery schedule, permissible delay in payment etc. Decision regarding the shipment schedule and the size of shipment must be taken jointly by both vendor and buyer. The integration between them would result in reduction of wastage. Integration approach would minimize the integrated total cost of the inventory system. The stock level of inventoried item is continuously depleting due to the combined effect of its demand and deterioration. Deterioration of goods in the form of direct spoilage or gradual physical decay in the course of time is a realistic phenomena and hence it should be considered in inventory modeling. Food items, pharmaceuticals, chemicals, blood, drugs etc., are some examples of such products. Some items deteriorate constantly with time, while deterioration of some other items could be modelled with probability distributions. The control and maintenance of inventories for deteriorating items have received great attention in recent years. Demand rate may be deterministic (a constant and known or varying with time) or probabilistic ( a random variable which follows known probability distribution) throughout the entire time horizon. Several inventory models were developed in classical EOQ(Economic Order Quantity) and vendor-buyer integrated inventory system by many researchers with different assumptions on demand and deterioration rate.

Yang and Wee [1] have presented a collaborative inventory system for deteriorating items with finite replenishment rate, price-sensitive demand and permissible delay in payment. Several researchers have developed an integrated single-buyer single-supplier inventory model for deteriorating items under JIT environment [Chung and Wee [2], Jong and Wee [3] and Shah [4]]. Yang and Wee [5] have developed an economic ordering policy for deteriorating items with a constant production and demand rates. Wu [6] has proposed a deterministic inventory model for items with time varying demand, Weibull deterioration by allowing shortages. Wee et al. [7] have analysed an integrated two stage inventory model for Weibull deteriorating items by assuming a constant demand rate and limited retailer storage space. Chung and Wee [8] have investigated an integrated production inventory model for Weibull deteriorating items considering stock level dependent demand rate. Chaudhary and Sharma [9] have developed an inventory model with Weibull deterioration rate and trapezoidal type demand rate for items in the inventory. Amutha and Chandrasekaran [10] have studied an inventory model with three parameter Weibull deterioration rate and price dependent demand rate.

In all the above said papers, demand for items is assumed to be constant for the entire time horizon. It may not be true for all types of items. Demand for items such as newly launched electronic components, fashionable clothes, cosmetic products, automobiles etc., the demand rate increases at the beginning up to a certain time and afterwards it stabilizes and becomes constant. Such type of demand rate is known as ramp type demand rate. Several researchers have developed inventory models with ramp type demand rate. [Panda et al. [11], Jain and Kumar [12], Karmakar and Choudhury 
[13]]. Panda et al. [14] developed an inventory model for non-instantaneous deteriorating items with price and time dependent ramp type demand rate. The effects of inflation and time discounting on an EOQ model was studied by Valliathal and Uthayakumar [15]. They have considered ramp type demand rate and Weibull deteriorating/ameliorating items with partial backlogging of unsatisfied demand.

Demand for certain type of products is considered to follow three different phases - initial phase of increasing demand, second phase of steady demand and third phase of decreasing demand when the product becomes outdated and it becomes zero. This phenomenon is generally known as three phase ramp type demand. This form of demand function is commonly used to describe the demand for fashion goods. The demand function is in the form of trapezium. Hence some authors have considered it as trapezoidal type demand. Many researchers have discussed inventory models with trapezoidal type demand rate. Cheng and Wang [16] proposed an inventory replenishment policy for deteriorating items with trapezoidal type demand rate allowing shortages. Cheng et al. [17] derived a mathematical model for time dependent deteriorating items with trapezoidal type demand rate and partial backlogging of unsatisfied demand. Chuang et al. [18] extended the work of Cheng et al. [17] considering the pricing policies in marketing. Wu et al. [19] discussed two inventory systems starting with and without shortages with trapezoidal type demand, time dependent deterioration rate and partial backlogging.

Shah et al. [20] developed an inventory model for vendor-buyer system with different deterioration rates for both vendor and buyer. The authors have assumed trapezoidal demand rate for both vendor and buyer where demand rate increases linearly in the first phase, constant in the second phase and decreases exponentially in the third phase. But it has an error in the mathematical formulation of the model for buyer. Trapezoidal demand rate is considered for vendor in the intervals $\left[0, u_{1}\right],\left[u_{1}, u_{2}\right]$ and $\left[u_{2}, T\right]$. They have assumed changes in the demand pattern occurring at time points $u_{1}$ and $u_{2},\left(u_{1}<u_{2}\right)$ in the interval $[0, T]$. The authors have assumed the same trapezoidal demand rate for the buyer, again assuming the change in the demand pattern occurring at time points $u_{1}$ and $u_{2},(u 1<u 2)$ in the interval $\left[0, T_{b}\right]$ where $T_{b}=T / n, n$ being the number of orders during the cycle time $T$. This assumption is completely unrealistic since the time points $u_{1}, u_{2}$ for the vendor are completely different from similar time points for the buyer. Further, the demand pattern for the buyer repeats in every interval $\left[0, T_{b}\right],\left[T_{b}, 2 T_{b}\right], \ldots$, $\left[(n-1) T_{b}, T\right]$. In our model, we have considered the most general form of ramp type demand pattern for both vendor and buyer as in Panda et al. [11]. In the first phase, the demand rate is exponentially increasing; in the second phase it becomes constant; and in the third phase, it is exponentially decreasing. The cycle length $T$ is divided into three intervals $[0, \mu],[\mu, \gamma]$ and $[\gamma, T]$ for both vendor and buyer; $\mu$ and $\gamma$ are the time points where the demand rate changes from increasing to constant and constant to decreasing pattern respectively. We have considered $n_{1}, n_{2}$ and $n_{3}$ as the number of shipments for the buyer in the three intervals respectively which is more realistic than considering a fixed number of $n$ deliveries as assumed in Shah et al. [20]. Further, we have studied the vendor buyer integrated inventory model when the items in the inventory deteriorate constantly. Since ramp type demand is considered for items which have a specific/short life span in the market, like fashion goods, shortages are not allowed. Assumptions which are made to develop the model and notations which are used in this paper are listed in section 2. In the section 3, the mathematical formulation, analytical approach to solve the model and the solution procedure are given. Numerical example to validate the developed model is considered in section 4 . In this section, we have studied the effects of changes in the parameter values on the optimum solution. Summary of the paper is given in section 5 .

\section{ASSUMPTIONS AND NOTATIONS}

The proposed model is developed using the following assumptions and notations

\subsection{Assumptions}

The following assumptions are made in developing the vendor-buyer inventory model.

1. The function $f(t)$ of three phase ramp type demand rate as given in Panda et al. [11] is given by

$$
\begin{aligned}
f(t)= & a \exp [b\{t-(t-\mu) H(t, \mu)-(t-\gamma) H(t, \gamma)\}], \\
& 0<\mu<\gamma
\end{aligned}
$$

where $a>0$ is the initial demand rate and $b>0$ is the rate with which the demand rate increases. $H(t, \mu)$ and $H(t, \gamma)$ are well-known Heaviside's functions respectively and are defined as

$$
\begin{aligned}
& H(t, \mu)= \begin{cases}1, & \text { if } t \geq \mu \\
0, & \text { if } t<\mu\end{cases} \\
& H(t, \gamma)= \begin{cases}1, & \text { if } t \geq \gamma \\
0, & \text { if } t<\gamma\end{cases}
\end{aligned}
$$

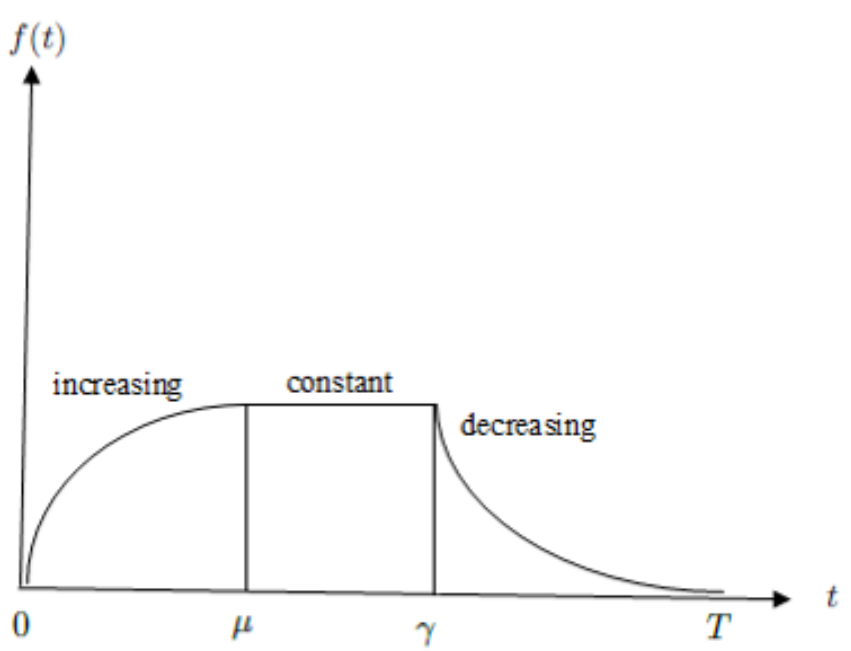

Figure 1: Behaviour of demand rate with respect to time 
Here demand increases exponentially up to time $\mu$ and becomes steady in between $\mu$ and $\gamma$. Finally, after time $\gamma$ it decreases exponentially and becomes zero. The behaviour of demand pattern is depicted in Figure 1.

2. A single vendor single buyer inventory system with single item is considered.

3. Shortage of the item is not allowed.

4. The lead-time is zero or negligible.
5. Complete cooperation of vendor and buyer is considered.

6. The number of shipments by the vendor is in three phases $[0, \mu],[\mu, \gamma]$ and $[\gamma, T]$ and they are integer valued.

7. Item in the inventory deteriorates constantly.

8. The deteriorated units can neither be repaired nor replaced during the cycle time.

9. Multiple deliveries per order are considered.

\subsection{Notations}

Notations used throughout this paper are

$\theta \quad$ Deterioration rate of items

$T \quad$ Time length of each cycle (a decision variable)

$I_{v 1}(t) \quad$ Inventory level for vendor when $t$ is between 0 and $\mu$

$I_{v 2}(t) \quad$ Inventory level for vendor when $t$ is between $\mu$ and $\gamma$

$I_{v 3}(t) \quad$ Inventory level for vendor when $t$ is between $\gamma$ and $T$

$n_{1} \quad$ Number of deliveries per cycle time before $\mu$ (a decision variable), integer valued

$n_{2} \quad$ Number of deliveries per cycle time between $\mu$ and $\gamma$ (a decision variable), integer valued

$n_{3} \quad$ Number of deliveries per cycle time between $\gamma$ and $T$ (a decision variable), integer valued

$t_{1} \quad$ Delivery cycle time for buyer in years before $\mu$

$t_{2} \quad$ Delivery cycle time for buyer in years between $\mu$ and $\gamma$

$t_{3} \quad$ Delivery cycle time for buyer in years between $\gamma$ and $T$

$I_{b 1 i}(t) \quad$ Inventory level for buyer when $t$ is between 0 and $\mu, i=1,2, \ldots, n_{1}$

$I_{b 2 j}(t) \quad$ Inventory level for buyer when $t$ is between $\mu$ and $\gamma, j=1,2, \ldots, n_{2}$

$I_{b 3 k}(t) \quad$ Inventory level for buyer when $t$ is between $\gamma$ and $T, k=1,2, \ldots, n_{3}$

$h_{v} \quad$ Holding cost per unit per unit time for vendor

$h_{b} \quad$ Holding cost per unit per unit time for buyer

$A_{v} \quad$ Vendor's set up cost per cycle time

$A_{b} \quad$ Ordering cost per order for buyer

$C_{d v} \quad$ Unit deteriorating cost for vendor

$C_{d b} \quad$ Unit deteriorating cost for buyer

$O C V \quad$ Set up cost per unit time for vendor

$D C V \quad$ Deterioration cost per unit time for vendor

$H C V \quad$ Holding cost per unit time for vendor

$T C V \quad$ Total cost per unit time for vendor

$O C B \quad$ Ordering cost per unit time for buyer

$D C B \quad$ Deterioration cost per unit time for buyer

$H C B$ Inventory holding cost per unit time for buyer

$T C B \quad$ Total cost per unit time for buyer

$T C \quad$ Integrated total cost

$q_{1 i} \quad$ Size of $i^{t h}$ shipment from the vendor to the buyer before $\mu, i=1,2,3, \ldots, n_{1}$

$q_{2 j} \quad$ Size of $j^{t h}$ shipment from the vendor to the buyer between $\mu$ and $\gamma j=1,2,3, \ldots, n_{2}$

$q_{3 k} \quad$ Size of $k^{t h}$ shipment from the vendor to the buyer between $\gamma$ and $T k=1,2,3, \ldots, n_{3}$

\section{MATHEMATICAL MODEL AND SOLUTION}

We are developing a single-vendor single-buyer integrated inventory model for deteriorating items with ramp type demand rate in three phases for both vendor and buyer. The objective of this problem is to determine the optimal number of shipments from the vendor to the buyer and the optimal cycle length in order to minimize the integrated total cost. Since we consider ramp type demand in three phases, the cycle length $\mathrm{T}$ is divided into three intervals $[0, \mu],[\mu, \gamma]$ and $[\gamma, \mathrm{T}]$.

\section{Vendor's inventory system:}

Initial inventory level for vendor that is at time $\mathrm{t}=0$ is $S$. Inventory depletes due to demand and deterioration throughout the cycle. Inventory level reduces to $Q$ at time $\mathrm{t}=\mu$, to $P$ at $\mathrm{t}=\gamma$ and becomes zero at $\mathrm{t}=T$. The behaviour of the vendor's 
inventory system at any time during a given cycle is portrayed in Figure 2.

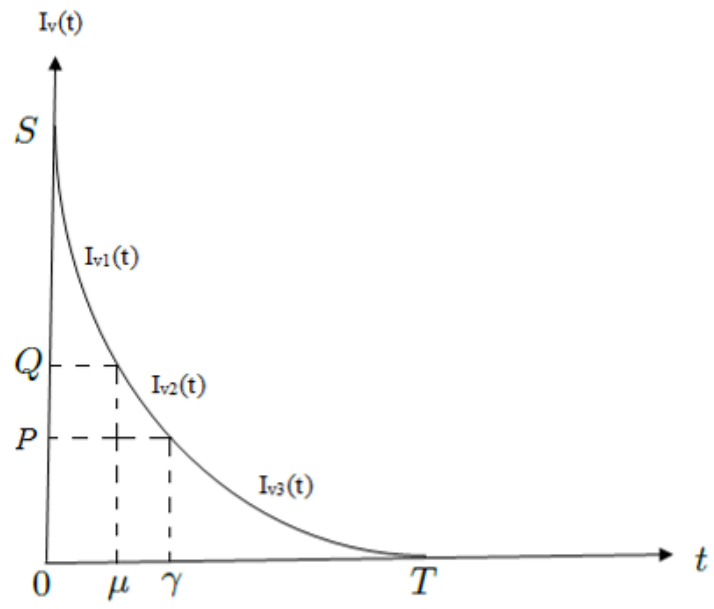

Figure 2: Inventory level for vendor

The vendor's inventory system at any time $t$ during the three intervals can be described by the following differential equations

$$
\frac{d I_{v 1}(t)}{d t}+\theta I_{v 1}(t)=-a e^{b t}, \quad 0 \leq t \leq \mu
$$

with initial condition $I_{v 1}(0)=S$.

$$
\frac{d I_{v 2}(t)}{d t}+\theta I_{v 2}(t)=-a e^{b \mu}, \quad \mu \leq t \leq \gamma
$$

with boundary condition $I_{v 1}(\mu)=I_{v 2}(\mu)=Q$.

$$
\frac{d I_{v 3}(t)}{d t}+\theta I_{v 3}(t)=-a e^{-b[t-(\mu+\gamma)]}, \quad \gamma \leq t \leq T
$$

with boundary condition $I_{v 3}(T)=0$.

The solutions of these differential equations are

$$
\begin{gathered}
I_{v 1}(t)=S e^{-\theta t}-\frac{a}{b+\theta}\left(e^{b t}-e^{-\theta t}\right), \quad 0 \leq t \leq \mu \\
I_{v 2}(t)=e^{\theta(\mu-t)}\left[Q+\frac{a e^{b \mu}}{\theta}\right]-\frac{a e^{b \mu}}{\theta}, \quad \mu \leq t \leq \gamma \\
I_{v 3}(t)=\frac{a e^{b(\mu+\gamma)}}{b}\left[e^{-b t}-e^{-b T}\right] e^{-\theta t}, \quad \gamma \leq t \leq T
\end{gathered}
$$

From Figure 2, $I_{v 1}(0)=S$ and $I_{v 1}(\mu)=I_{v 2}(\mu)=Q$; hence from (4) and (5)

$$
S=e^{\theta \mu}\left[Q+\frac{a}{b+\theta}\left(e^{b \mu}-e^{-\theta \mu}\right)\right]
$$

From Figure 2, $I_{v 2}(\gamma)=I_{v 3}(\gamma)$; hence from (5) and (6)

$$
\begin{aligned}
Q= & \left(\frac{a}{b} e^{b(\mu+\gamma)}\left[e^{-b \gamma}-e^{-b T}\right] e^{-\theta \gamma}\right. \\
& \left.+\frac{a}{\theta} e^{b \mu}\left[1-e^{\theta(\mu-\gamma)}\right]\right) e^{\theta(\gamma-\mu)}
\end{aligned}
$$

From Figure 2, $I_{v 2}(\gamma)=\mathrm{P}$; hence from (5)

$$
P=e^{\theta(\mu-\gamma)}\left[Q+\frac{a e^{b \mu}}{\theta}\right]-\frac{a e^{b \mu}}{\theta},
$$

\section{Buyer's inventory system:}

We consider ramp type demand in three phases for buyer. There are $n_{1}$ deliveries each with delivery cycle time $t_{1}$ during the period $[0, \mu], n_{2}$ deliveries each with delivery cycle time $t_{2}$ during the period $[\mu, \gamma]$ and $n_{3}$ deliveries each with delivery cycle time $t_{3}$ during the period $[\gamma, T]$ per order from the vendor to the buyer. The behaviour of the buyer's inventory system at any time during a given cycle is portrayed in Figure 3.

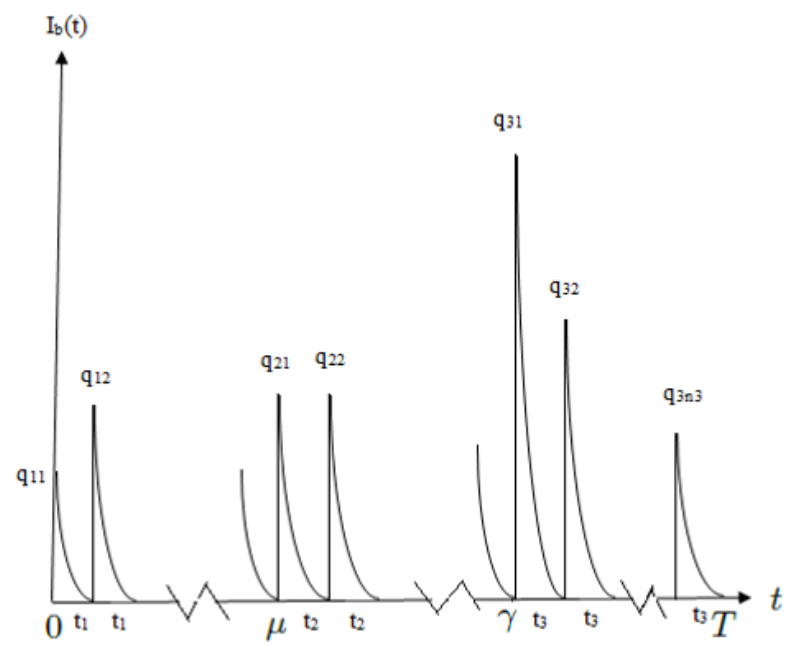

Figure 3: Inventory level for buyer

The buyer's inventory system at any time $t$ during the $i^{\text {th }}$ replenishment cycle $\left[(i-1) t_{1}, i t_{1}\right]$ can be described by the following differential equation:

$$
\frac{d I_{b 1 i}(t)}{d t}+\theta I_{b 1 i}(t)=-a e^{b t}, \quad(i-1) t_{1} \leq t \leq i t_{1}
$$

with boundary condition $I_{b 1 i}\left(i t_{1}\right)=0$ where $i=1,2,3, \ldots, n_{1}$ and $n_{1} t_{1}=\mu$

The buyer's inventory system at any time $t$ during the $j^{t h}$ replenishment cycle 
$\left[\mu+(j-1) t_{2}, \mu+j t_{2}\right]$ can be described by the following differential equation:

$$
\begin{aligned}
\frac{d I_{b 2 j}(t)}{d t}+\theta I_{b 2 j}(t)=- & a e^{b \mu}, \\
& \mu+(j-1) t_{2} \leq t \leq \mu+j t_{2}
\end{aligned}
$$

with boundary condition $I_{b 2 j}\left(\mu+j t_{2}\right)=0$ and where $j=1,2,3, \ldots, n_{2}$ and $n_{2} t_{2}=\gamma-\mu$

The buyer's inventory system at any time $t$ during the $k^{t h}$ replenishment cycle

$\left[\gamma+(k-1) t_{3}, \gamma+k t_{3}\right]$ can be described by the following differential equation:

$$
\begin{aligned}
\frac{d I_{b 3 k}(t)}{d t}+\theta I_{b 3 k}(t) & =-a e^{-b[t-(\mu+\gamma)]} \\
& \gamma+(k-1) t_{3} \leq t \leq \gamma+k t_{3}
\end{aligned}
$$

with boundary condition $I_{b 3 k}\left(\left(\gamma+k t_{3}\right)\right)=0$ and where $k=1,2,3, \ldots, n_{3}$ and $n_{3} t_{3}=T-\gamma$

The solutions of these differential equations are

$$
\begin{gathered}
I_{b 1 i}(t)=\frac{a}{b+\theta}\left(e^{(b+\theta) i t_{1}-\theta t}-e^{b t}\right), \\
0 \leq t \leq T_{b i}, \quad(i-1) t_{1} \leq t \leq i t_{1} \\
I_{b 2 j}(t)=\frac{a}{\theta} e^{b \mu}\left[e^{\theta\left(\mu+j t_{2}\right)-\theta t}-1\right], \\
\mu+(j-1) t_{2} \leq t \leq \mu+j t_{2} \\
I_{b 3 k}(t)=\frac{a}{\theta-b} e^{b(\mu+\gamma)}\left[e^{(\theta-b)\left(\gamma+k t_{3}\right)-\theta t}-e^{b t}\right], \\
\gamma+(k-1) t_{3} \leq t \leq \gamma+k t_{3}
\end{gathered}
$$

From Figure $3, I_{b 1 i}\left((i-1) t_{1}\right)=q_{1 i}$; hence from (13)

$$
q_{1 i}=\frac{a}{b+\theta} e^{b i t_{1}}\left[e^{\theta t_{1}}-e^{-b t_{1}}\right], \quad i=1,2, \ldots, n_{1}
$$

From Figure $3, I_{b 2 j}\left(\mu+(j-1) t_{2}\right)=q_{2 j}$; hence from (14)

$$
q_{2 j}=\frac{a}{\theta} e^{b \mu}\left[e^{\theta t_{2}}-1\right], \quad j=1,2, \ldots, n_{2}
$$

From Figure $3, I_{b 3 k}\left(\gamma+(k-1) t_{3}\right)=q_{3 k}$; hence from (15)

$$
q_{3 k}=\frac{a}{\theta-b} e^{b\left(\mu-k t_{3}\right)}\left[e^{\theta t_{3}}-e^{b t_{3}}\right], \quad k=1,2, \ldots, n_{3}
$$

\section{Buyer's total cost}

During the cycle time $T$, there are $n_{1}$ replenishments between $[0, \mu], n_{2}$ replenishments between $[\mu, \gamma]$ and $n_{3}$ replenishments between $[\gamma, T]$ to the buyer.
The buyer's ordering cost is

$$
O C B=\frac{\left(n_{1}+n_{2}+n_{3}\right) A_{b}}{T}
$$

The buyer's holding cost is

$$
\begin{aligned}
H C B= & \frac{h_{b}}{T}\left[\sum_{i=1}^{n_{1}} \int_{(i-1) t_{1}}^{i t_{1}} I_{b 1 i}(t) d t+\sum_{j=1}^{n_{2}} \int_{\mu+(j-1) t_{2}}^{\mu+j t_{2}} I_{b 2 j}(t) d t\right. \\
& \left.+\sum_{k=1}^{n_{3}} \int_{\gamma+(k-1) t_{3}}^{\gamma+k t_{3}} I_{b 3 k}(t) d t\right]
\end{aligned}
$$

The buyer's deteriorating cost is

$$
\begin{aligned}
D C B= & \frac{C_{d b}}{T}\left[\sum_{i=1}^{n_{1}}\left(q_{1 i}-\int_{(i-1) t_{1}}^{i t_{1}} a e^{b t} d t\right)\right. \\
& +\sum_{j=1}^{n_{2}}\left(q_{2 j}-\int_{\mu+(j-1) t_{2}}^{\mu+j t_{2}} a e^{b \mu} d t\right) \\
& \left.+\sum_{k=1}^{n_{3}}\left(q_{3 k}-\int_{\gamma+(k-1) t_{3}}^{\gamma+k t_{3}} a e^{-b(t-(\mu+\gamma))} d t\right)\right]
\end{aligned}
$$

Therefore the total cost for the buyer is

$$
T C B=O C B+H C B+D C B
$$

\section{Vendor's total cost}

The vendor's set up cost is

$$
O C V=\frac{A_{v}}{T}
$$

The vendor's holding cost is

$$
\begin{aligned}
H C V= & \frac{h_{v}}{T}\left[\int_{0}^{\mu} I_{v 1}(t) d t+\int_{\mu}^{\gamma} I_{v 2}(t) d t\right. \\
& +\int_{\gamma}^{T} I_{v 3}(t) d t-\sum_{i=1}^{n_{1}} \int_{(i-1) t_{1}}^{i t_{1}} I_{b 1 i}(t) d t \\
& -\sum_{j=1}^{n_{2}} \int_{\mu+(j-1) t_{2}}^{\mu+j t_{2}} I_{b 2 j}(t) d t \\
& \left.-\sum_{k=1}^{n_{3}} \int_{\gamma+(k-1) t_{3}}^{\gamma+k t_{3}} I_{b 3 k}(t) d t\right]
\end{aligned}
$$

The vendor's deteriorating cost is

$$
D C V=\frac{C_{d v}}{T}\left[S-\left(\sum_{i=1}^{n_{1}} q_{1 i}+\sum_{j=1}^{n_{2}} q_{2 j}+\sum_{k=1}^{n_{3}} q_{3 k}\right)\right]
$$


Since shortages are not allowed,

$$
S-\left(\sum_{i=1}^{n_{1}} q_{1 i}+\sum_{j=1}^{n_{2}} q_{2 j}+\sum_{k=1}^{n_{3}} q_{3 k}\right)
$$

cannot be negative. To ensure this, we include the constraint

$$
S \geq\left(\sum_{i=1}^{n_{1}} q_{1 i}+\sum_{j=1}^{n_{2}} q_{2 j}+\sum_{k=1}^{n_{3}} q_{3 k}\right)
$$

Therefore the total cost for the vendor is

$$
T C V=O C V+H C V+D C V
$$

The integrated total cost for the vendor and the buyer is

$$
T C=T C B+T C V
$$

The problem of determining optimal decision for the inventory model reduces to the following optimization problem.

$$
\left.\begin{array}{rl}
\text { Minimize } & T C \\
\text { subject to constraints: } & S \geq\left(\sum_{i=1}^{n_{1}} q_{1 i}+\sum_{j=1}^{n_{2}} q_{2 j}+\sum_{k=1}^{n_{3}} q_{3 k}\right) \\
& \text { and } T \geq \gamma .
\end{array}\right\}
$$

\section{Solution procedure}

The objective of the problem is to determine the optimal values of the number of shipments $n_{1}, n_{2}$ and $n_{3}$, and the cycle length $T$ that minimize $T C$.

Since the number of shipments $n_{1}, n_{2}$ and $n_{3}$ are integer valued, we can determine these values by the following iterative procedure.

Step 1: For a choice of $\left(n_{1}, n_{2}, n_{3}\right), \quad n_{1}=1,2,3, \ldots$, $n_{2}=1,2,3, \ldots$ and $n_{3}=1,2,3, \ldots, T C$ is a function of $T$ only. Take the partial derivative of $T C$ with respect to $T$ and equate to zero.

$$
\frac{\partial T C}{\partial T}=0
$$

Solve this equation for $T$ and then calculate $T C$ by equation (29).

Step 2: The optimal values of $n_{1}, n_{2}, n_{3}$, and $T$ denoted by $n_{1}^{*}, n_{2}^{*}, n_{3}^{*}$, and $T^{*}$ are obtained such that the $T C$ is minimum.

Step 3: Find $t_{1}^{*}, t_{2}^{*}$ and $t_{3}^{*}$ given by $t_{1}^{*}=\frac{\mu}{n_{1}}, t_{2}^{*}=\frac{(\gamma-\mu)}{n_{2}}$ and $t_{3}^{*}=\frac{T-\gamma}{n_{3}}$

Step 4: Find $S^{*}, Q^{*}$ and $P^{*}$ from (7), (8) and (9) respectively.

Step 5: Find $q_{1 i}^{*}, q_{2 j}^{*}$ and $q_{3 k}^{*}$ from (16), (17) and (18) respectively where $\mathrm{i}=1,2, \ldots, n_{1}, \mathrm{j}=1,2, \ldots, n_{2}$ and $\mathrm{k}=1,2, \ldots, n_{3}$.

\section{NUMERICAL EXAMPLE}

To validate the model, we consider the following numerical example. $A_{v}=\$ 600, A_{b}=\$ 100, h_{v}=\$ 0.9, h_{b}=\$ 1.1, C_{d v}=\$ 2.0$, $C_{d b}=\$ 2.5, \mathrm{a}=100, \mathrm{~b}=0.08, \theta=0.1, \mu=0.12$ years, $\gamma=0.3$ years.

Since the integrated total cost given in equation (29) is a

\begin{tabular}{|c|c|c|}
\hline$\left(n_{1}, n_{2}, n_{3}\right)$ & $T$ & $T C$ \\
\hline$(1,1,1)$ & 0.509 & 1794.98 \\
\hline$(1,1,2)$ & 0.597 & 1704.96 \\
\hline$(1,1,3)$ & 0.665 & 1686.53 \\
\hline$(1,1,4)$ & 0.722 & 1696.55 \\
\hline$(1,2,1)$ & 0.546 & 1859.60 \\
\hline$(1,2,2)$ & 0.649 & 1726.72 \\
\hline$(1,2,3)$ & 0.728 & 1683.07 \\
\hline$(1,2,4)$ & 0.795 & $1673.17 *$ \\
\hline$(1,2,5)$ & 0.854 & 1678.74 \\
\hline$(1,3,1)$ & No feasible point & \\
\hline$(1,3,2)$ & 0.664 & 1839.59 \\
\hline$(1,3,3)$ & 0.747 & 1775.71 \\
\hline$(1,3,4)$ & 0.817 & 1751.61 \\
\hline$(1,3,5)$ & 0.879 & 1746.81 \\
\hline$(1,3,6)$ & 0.935 & 1753.63 \\
\hline$(2,1,1)$ & 0.526 & 1928.54 \\
\hline$(2,1,2)$ & 0.621 & 1802.13 \\
\hline$(2,1,3)$ & 0.694 & 1762.57 \\
\hline$(2,1,4)$ & 0.756 & 1755.33 \\
\hline$(2,1,5)$ & 0.81 & 1766.16 \\
\hline$(2,2,1)$ & 0.56 & 1992.88 \\
\hline$(2,2,2)$ & 0.669 & 1826.26 \\
\hline$(2,2,3)$ & 0.753 & 1762.07 \\
\hline$(2,2,4)$ & 0.824 & 1737.31 \\
\hline$(2,2,5)$ & 0.886 & 1733.59 \\
\hline$(2,2,6)$ & 0.944 & 1737.66 \\
\hline
\end{tabular}
function of four variables $n_{1}, n_{2}, n_{3}, T$, we have implemented the solution procedure using patternsearch in Optimization Tool-MATLAB Version R2011a.

Table 1: Time and total cost for different combinations of number of deliveries $\left(n_{1}, n_{2}, n_{3}\right)$

$*$ Optimal solution from the integrated perspective.

We obtain the optimal solution as follows:

$n_{1}^{*}=1, n_{2}^{*}=2, n_{3}^{*}=4, T^{*}=0.795$ years, $T C^{*}=1673.17$ (Table 1 ).

$S^{*}=79.69, \quad Q^{*}=66.75, \quad P^{*}=47.55, \quad t_{1}^{*}=0.12$ years,$t_{2}^{*}=0.09$ years, $t_{3}^{*}=0.124$ years.

$q_{11}^{*}=12.13, \quad q_{21}^{*}=9.12, \quad q_{22}^{*}=9.12, \quad q_{31}^{*}=12.50, \quad q_{32}^{*}=12.38$, $q_{33}^{*}=12.26, q_{34}^{*}=12.14$.

\section{Sensitivity analysis}

To study the effect of changes in parameters on optimal solution, we have carried out sensitivity analysis. To analyse the result we have considered PICD (Percentage of Integrated 
International Journal of Applied Engineering Research ISSN 0973-4562 Volume 15, Number 10 (2020) pp. 1039-1048 (C) Research India Publications. https://dx.doi.org/10.37622/IJAER/15.10.2020.1039-1048

total Cost Difference) which is defined as:

$P I C D=\frac{\left(T C-T C^{*}\right)}{T C^{*}}$
The results of the sensitivity analysis executed by changing the value of each of the parameters by $-20 \%,-10 \%, 10 \%$ and $20 \%$ and keeping all other parameters unchanged are shown in Tables 2 to 9 .

Table 2: Sensitivity analysis when $A_{v}$ and $A_{b}$ are changed

\begin{tabular}{llllll}
\hline$A_{v}$ & 480 & 540 & $\{600\}$ & 660 & 720 \\
$A_{b}$ & 80 & 90 & $\{100\}$ & 110 & 120 \\
\hline$\left(n_{1}, n_{2}, n_{3}\right)$ & $(1,2,4)$ & $(1,2,4)$ & $(1,2,4)$ & $(1,2,4)$ & $(1,2,4)$ \\
$T C$ & 1345.97 & 1509.57 & $1673.17 *$ & 1836.77 & 2000.36 \\
$T$ & 0.795 & 0.795 & 0.795 & 0.795 & 0.795 \\
$P I C D$ & -0.20 & -0.10 & 0.00 & 0.10 & 0.20 \\
\hline
\end{tabular}

*: Optimal total cost; \{\} : Base column

Table 3: Sensitivity analysis when $h_{v}$ and $h_{b}$ are changed

\begin{tabular}{llllll}
\hline$h_{v}$ & 0.72 & 0.81 & $\{0.9\}$ & 0.99 & 1.08 \\
$h_{b}$ & 0.88 & 0.99 & $\{1.1\}$ & 1.21 & 1.32 \\
\hline$\left(n_{1}, n_{2}, n_{3}\right)$ & $(1,2,4)$ & $(1,2,4)$ & $(1,2,4)$ & $(1,2,4)$ & $(1,2,4)$ \\
$T C$ & 1666.02 & 1669.59 & $1673.17 *$ & 1676.74 & 1680.32 \\
$T$ & 0.795 & 0.795 & 0.795 & 0.795 & 0.795 \\
$P I C D$ & -0.004 & -0.002 & 0.00 & 0.002 & 0.004 \\
\hline
\end{tabular}

*: Optimal total cost; \{\} : Base column

Table 4: Sensitivity analysis when $C_{d v}$ and $C_{d b}$ are changed

\begin{tabular}{llllll}
\hline$C_{d v}$ & 1.6 & 1.8 & $\{2.0\}$ & 2.2 & 2.4 \\
$C_{d b}$ & 2.00 & 2.25 & $\{2.5\}$ & 2.75 & 3.00 \\
\hline$\left(n_{1}, n_{2}, n_{3}\right)$ & $(1,2,4)$ & $(1,2,4)$ & $(1,2,4)$ & $(1,2,4)$ & $(1,2,4)$ \\
$T C$ & 1672.88 & 1672.88 & $1673.17 *$ & 1673.31 & 1673.46 \\
$T$ & 0.795 & 0.795 & 0.795 & 0.795 & 0.795 \\
$P I C D$ & -0.00 & -0.0 & 0.00 & 0.00 & 0.00 \\
\hline
\end{tabular}

*: Optimal total cost; \{\} : Base column

Table 5: Sensitivity analysis when $a$ changed

\begin{tabular}{llllll}
\hline$a$ & 80 & 90 & $\{100\}$ & 110 & 120 \\
\hline$\left(n_{1}, n_{2}, n_{3}\right)$ & $(1,2,4)$ & $(1,2,4)$ & $(1,2,4)$ & $(1,2,4)$ & $(1,2,4)$ \\
$T C$ & 1665.73 & 1669.45 & $1673.17^{*}$ & 1676.89 & 1680.61 \\
$T$ & 0.795 & 0.795 & 0.795 & 0.795 & 0.795 \\
$P I C D$ & -0.004 & -0.002 & 0.00 & 0.002 & 0.004 \\
\hline
\end{tabular}

*: Optimal total cost; \{\} : Base column

Table 6: Sensitivity analysis when $b$ changed

\begin{tabular}{llllll}
\hline$b$ & 0.064 & 0.072 & $\{0.08\}$ & 0.088 & 0.096 \\
\hline$\left(n_{1}, n_{2}, n_{3}\right)$ & $(1,2,4)$ & $(1,2,4)$ & $(1,2,4)$ & $(1,2,4)$ & $(1,2,4)$ \\
$T C$ & 1675.21 & 1674.19 & $1673.17 *$ & 1672.15 & 1671.13 \\
$T$ & 0.794 & 0.794 & 0.795 & 0.795 & 0.796 \\
$P I C D$ & 0.001 & 0.00 & 0.00 & -0.00 & -0.001 \\
\hline
\end{tabular}

*: Optimal total cost; \{\} : Base column 
International Journal of Applied Engineering Research ISSN 0973-4562 Volume 15, Number 10 (2020) pp. 1039-1048 (C) Research India Publications. https://dx.doi.org/10.37622/IJAER/15.10.2020.1039-1048

Table 7: Sensitivity analysis when $\theta$ changed

\begin{tabular}{llllll}
\hline$\theta$ & 0.08 & 0.09 & $\{0.1\}$ & 0.11 & 0.12 \\
\hline$\left(n_{1}, n_{2}, n_{3}\right)$ & $\begin{array}{l}\text { No } \\
\text { feasible }\end{array}$ & $(1,2,4)$ & $(1,2,4)$ & $(1,2,4)$ & $(1,2,4)$ \\
& point & & & & \\
$T C$ & - & 1673.10 & $1673.17 *$ & 1672.25 & 1672.32 \\
$T$ & - & 0.795 & 0.795 & 0.795 & 0.795 \\
$P I C D$ & - & -0.00 & 0.00 & -0.00 & -0.00 \\
\hline
\end{tabular}

*: Optimal total cost; \{\}$:$ Base column

Table 8: Sensitivity analysis when $\mu$ changed

\begin{tabular}{llllll}
\hline$\mu$ & 0.096 & 0.108 & $\{0.12\}$ & 0.132 & 0.144 \\
\hline$\left(n_{1}, n_{2}, n_{3}\right)$ & $(1,2,4)$ & $(1,2,4)$ & $(1,2,4)$ & $(1,1,3)$ & $(1,1,3)$ \\
$T C$ & 1668.18 & 1668.21 & $1673.17 *$ & 1675.29 & 1669.44 \\
$T$ & 0.797 & 0.797 & 0.795 & 0.67 & 0.672 \\
$P I C D$ & -0.003 & -0.003 & 0.00 & 0.001 & -0.002 \\
\hline
\end{tabular}

*: Optimal total cost; \{\} : Base column

Table 9: Sensitivity analysis when $\gamma$ changed

\begin{tabular}{llllll}
\hline$\gamma$ & 0.24 & 0.27 & $\{0.3\}$ & 0.33 & 0.36 \\
\hline$\left(n_{1}, n_{2}, n_{3}\right)$ & $(1,1,3)$ & $(1,1,3)$ & $(1,2,4)$ & $(1,2,4)$ & $(1,2,4)$ \\
$T C$ & 2075.13 & 1855.04 & $1673.17 *$ & 1522.58 & 1400.56 \\
$T$ & 0.537 & 0.603 & 0.795 & 0.877 & 0.959 \\
$P I C D$ & 0.24 & 0.11 & 0.00 & -0.09 & -0.16 \\
\hline
\end{tabular}

*: Optimal total cost; \{\} : Base column

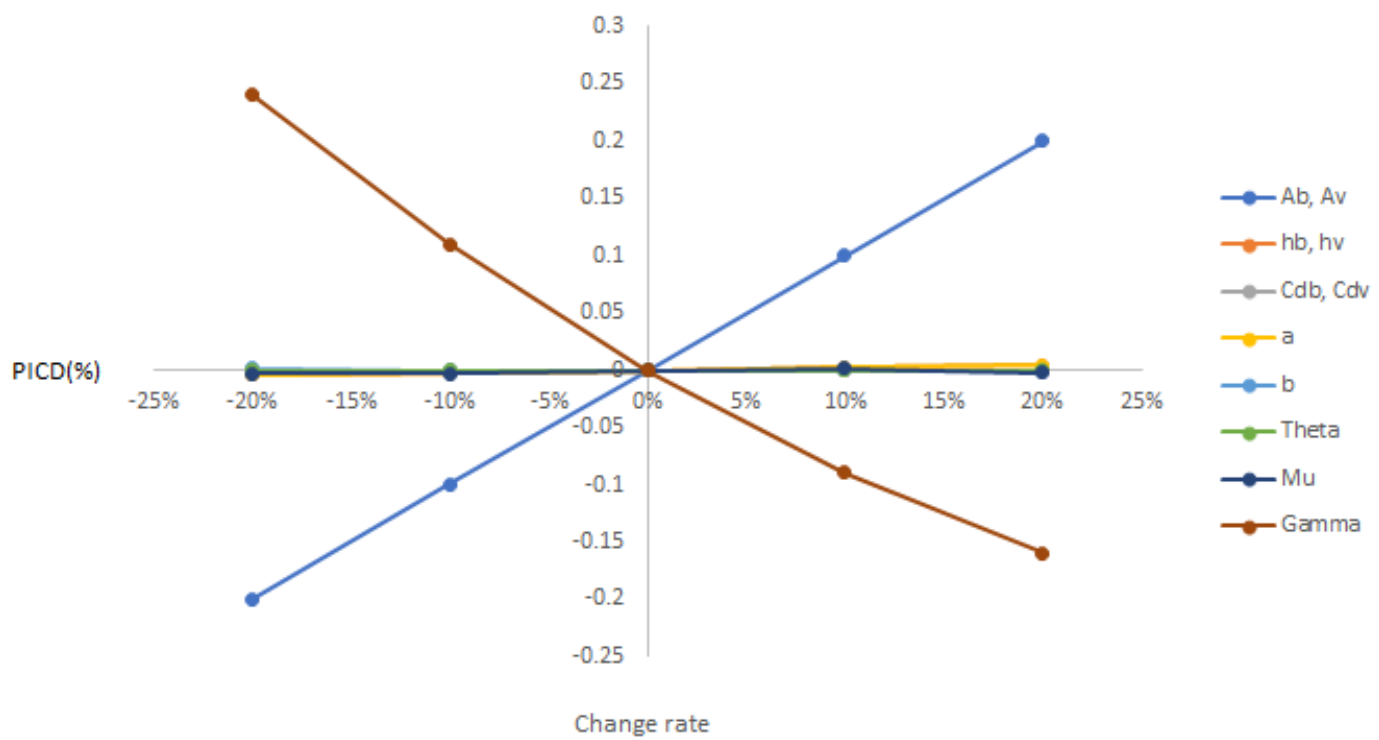

Figure 4: PICD vs. change rate of various parameters 
International Journal of Applied Engineering Research ISSN 0973-4562 Volume 15, Number 10 (2020) pp. 1039-1048

(C)Research India Publications. https://dx.doi.org/10.37622/IJAER/15.10.2020.1039-1048

\section{CONCLUSIONS}

The sensitivity analysis leads to the following conclusions (refer Tables 2 to 9 and Figure 4)

- The percentage change in integrated total cost (PICD) is highly significant for changes in the values of $\left(A_{v}, A_{b}\right)$ and $\gamma$. It is less significant for changes in the values of $\left(h_{v}, h_{b}\right), \mathrm{a}, \mu$. It is insignificant for changes in the values of $\left(C_{d v}, C_{d b}\right), \mathrm{b}, \theta$.

- The value of $n_{i}$ where $i=1,2,3$, are not sensitive for the parameters $\left(A_{v}, A_{b}\right),\left(h_{v}, h_{b}\right),\left(C_{d v}, C_{d b}\right), \mathrm{a}, \mathrm{b}, \theta$. They are sensitive for the parameters $\mu$ and $\gamma$.

- The value of $\mathrm{T}$ is not sensitive for the parameters $\left(A_{v}, A_{b}\right),\left(h_{v}, h_{b}\right),\left(C_{d v}, C_{d b}\right), \mathrm{a}, \theta$. It is sensitive for the parameters $\mathrm{b}, \mu, \gamma$.

\section{SUMMARY}

We have developed an integrated inventory model for a single-vendor single-buyer scenario for single item. Items in the inventory deteriorate at a constant rate. We have considered the most general form of ramp type demand pattern in three phases for both vendor and buyer. Since the cycle length $\mathrm{T}$, which is divided into $[0, \mu],[\mu, \gamma]$ and $[\gamma, T]$, depends on the demand rate, we consider $n_{1}, n_{2}, n_{3}$ as the number of shipments for the buyer in the three intervals respectively. This is more realistic than considering a fixed number deliveries for the entire time horizon T. Since shortages are not allowed, the level of initial inventory must be greater than or equal to the sum of all units delivered from the vendor to the buyer. Therefore, we have imposed the condition $S \geq$ $\left(\sum_{i=1}^{n_{1}} q_{1 i}+\sum_{j=1}^{n_{2}} q_{2 j}+\sum_{k=1}^{n_{3}} q_{3 k}\right)$. Since the cycle length $\mathrm{T}$ is a variable and it is divided into $[0, \mu],[\mu, \gamma]$ and $[\gamma, T]$, we have put a constraint $T \geq \gamma$. Since the integrated total cost is a function of four decision variables (three discrete variables and one continuous variable), it cannot be solved analytically. Hence, we obtain the optimal solution using patternsearch in Optimization Tool-MATLAB Version R2011a. Sensitivity analysis is also performed to analyse the effect of parameters on the optimal solution. It is observed from Table (9) that, total cost (TC) is minimized when the length of the time interval $[\mu, \gamma]$ increases.

\section{REFERENCES}

[1] Yang, P.C. and Wee, H.M., 2006, "A collaborative inventory system with permissible delay in payment for deteriorating items," Mathematical and Computer Modeling, Vol. 43, pp. 209-221.

[2] Chung, C.J. and Wee, H.M., 2008, "Scheduling and replenishment plan for an integrated deteriorating inventory model with stock-dependent selling rate," International Journal of Advanced Manufacturing Technology, Vol. 35, pp. 665-679.
[3] Jong, J.F. and Wee, H.M., 2008, "A near optimal solution for integrated production inventory supplier-buyer deteriorating model considering JIT delivery batch," International Journal of Computer Integrated Manufacturing, Vol. 21(3), pp. 289-300.

[4] Shah, N.H., 2011, "Single supplier-buyer integrated inventory model under multiple JIT delivery and stock-dependent demand," Journal of Mathematical Modeling and Algorithms, Vol. 10, pp. 293-305.

[5] Yang, P.C. and Wee, H.M., 2000, "Economic ordering policy of deteriorated item for vendor and buyer: An integrated approach," Production Planning \& Control: The Management of Operations, Vol. 11(5), pp. 474-480.

[6] Wu, K.S., 2002, "Deterministic inventory model for items with time varying demand, Weibull distribution deterioration and shortages," Yugoslav Journal of Operations Research, Vol. 12(1), pp. 61-71.

[7] Wee, H.M., Yu, J. and Law, S.T., 2004, “Collaboration inventory system with limited resources and Weibull distribution deterioration," Proceedings of the Fifth Asia Pacific Industrial Engineering and Management Systems Conference 2004, Vol. 34.7.1-34.7.16.

[8] Chung, C.J. and Wee, H.M., 2008, "An integrated production-inventory deteriorating model for pricing policy considering imperfect production, inspection planning and warranty-period and stock-level-dependent demand," International Journal of Systems Science, Vol. 39(8), pp. 823-837.

[9] Chaudhary, R.R. and Sharma, V., 2013, "Optimal inventory model with Weibull deterioration with trapezoidal demand and shortages," International Journal of Engineering Research \& Technology (IJERT), Vol. 2(3), pp. 1-10.

[10] Amutha, R. and Chandrasekaran, E., 2013, “An inventory model for deteriorating items with three parameter Weibull deterioration and price dependent demand," International Journal of Engineering Research \& Technology (IJERT), Vol. 2(5), pp. 1931-1935.

[11] Panda, S., Senapati, S. and Basu, M., 2008, "Optimal replenishment policy for perishable seasonal products in a season with ramp-type time dependent demand," Computers and Industrial Engineering, Vol. 54, pp. 301-314.

[12] Jain, S. and Kumar, M., 2010, "An EOQ inventory model for items with ramp type demand, three-parameter Weibull distribution deterioration and starting with shortage," Yugoslav Journal of Operations Research, Vol. 20(2), pp. 249-259.

[13] Karmakar, B. and Choudhury, K.D., 2014, "Inventory models with ramp-type demand for deteriorating items with partial backlogging and time-varying holding cost," Yugoslav Journal of Operations Research, Vol. 24(2), pp. 249-266. 
International Journal of Applied Engineering Research ISSN 0973-4562 Volume 15, Number 10 (2020) pp. 1039-1048

(C) Research India Publications. https://dx.doi.org/10.37622/IJAER/15.10.2020.1039-1048

[14] Panda, S., Saha, S. and Basu, M., 2013, “Optimal pricing policy and lot-sizing for perishable inventory with price and time dependent ramp-type demand," International Journal of Systems Science, Vol. 44(1), pp. 127-138.

[15] Valliathal, M. and Uthayakumar, R., 2013, "A study of inflation effects on an EOQ model for Weibull deteriorating/ameliorating items with ramp type of demand and shortages," Yugoslav Journal of Operations Research, Vol. 23(3), pp. 441-455.

[16] Cheng, M. and Wang, G., 2009, "A note on the inventory model for deteriorating items with trapezoidal type demand rate," Computers \& Industrial Engineering, Vol. 56, pp. 1296-1300.

[17] Cheng, M., Zhang, B. and Wang, G., 2011, “Optimal policy for deteriorating items with trapezoidal type demand and partial backlogging," Applied Mathematical Modelling, Vol. 35, pp. 3552-3560.

[18] Chuang, K.W., Lin, C.N. and Lan, C.H., 2013, “Order policy analysis for deteriorating inventory model with trapezoidal type demand rate," Journal of Networks, Vol. 8(8), pp. 1838-1844.

[19] Wu, J., Skouri, K., Teng, J.T. and Hu, Y., 2016, “Two inventory systems with trapezoidal-type demand rate and time-dependent deterioration and backlogging," Expert Systems With Applications, Vol. 46, pp. 367-379.

[20] Shah, N.H., Digeshkumar, B. and Shah, D.B., 2013, "Joint optimal policy for variable deteriorating inventory system of vendor-buyer ordering with trapezoidal demand," British Journal of Applied Science \& Technology, Vol. 3(1), pp. 160-173. 